\title{
Introduction to the Handbook of Research Methods in Careers
}

\author{
Wendy Murphy and Jennifer Tosti-Kharas
}

We are excited to introduce you to the Handbook of Research Methods in Careers. This Handbook serves as a comprehensive introduction to the methodologies that researchers use in the careers domain. The field of careers "explores people's lifelong succession of work experience, the structure of opportunity to work, and the relationship between careers and other aspects of life" (Academy of Management, 2020). As such, the field itself is multi-disciplinary and multi-level, as individual careers develop embedded in the context of organizations, families/societies, cultures and national geographies and as the scholars' disciplinary lenses may inform the level of analysis studied.

We felt the time was right for a handbook on careers research methods for a few reasons. First, careers as a phenomenon of study have unquestionably become more rich, dynamic, and complex than ever before. What started with a recognition that many careers are no longer unfolding within a single organization on a set, typically upward, path (e.g., Arthur \& Rousseau, 1996) at the turn of the new millennium has evolved into a series of highly individualized career paths (Cappelli \& Keller, 2013). The rise of novel employment relationships, like contract, freelance, and "gig" work, has changed the nature of the relationship between organizations and workers (e.g., Petriglieri, Ashford \& Wrzesniewski, 2019; Spreitzer, Cameron \& Garrett, 2017). Globalization has meant that people increasingly pursue expatriate assignments, and careers develop across geographical and cultural borders (Biemann, Fasang \& Grunow, 2011; Tams \& Arthur, 2007). The rise of technology enabled remote collaboration and work even before the rise of a global pandemic forced many to work from their homes (Spurk \& Straub, 2020). A turbulent few decades, marked by terror attacks, global recessions, and that same pandemic have led countless people to make career changes, both voluntary and involuntary (Akkermans, Richardson \& Kraimer, 2020; Briscoe, Henagan, Burton \& Murphy, 2012; Michaelson \& Tosti-Kharas, 2020). Aging Baby Boomers contemplated encore careers and transitions to retirement (Boveda \& Metz, 2016), as Millennials were categorized as non-committal job-hoppers (Ng, Schweitzer \& Lyons, 2010). We present this list, not as comprehensive nor exhaustive, but rather to illustrate that changes to the world around us affect our careers in numerous ways. This trend will likely continue, as the highly-anticipated "fourth industrial revolution" foretells artificial intelligence, automization, and technological unemployment, all of which will provide further shifts in people's careers (Schwab, 2016). What this means for careers scholars is that there is no shortage of interesting questions to ask, nor of innovative ways to study these 
questions, and we hope this Handbook can help inspire research that better helps us understand careers, now and in the future.

Second, perhaps as a natural response to the changes affecting people's actual careers, the field of careers research itself has witnessed a significant evolution. Early on, the field encompassed vocational development aiming to help people identify the starting occupation in their career - with the basic assumption that initial placement could carry one through to retirement - as well as the organizational human resource systems to help people progress along that track (see Arthur, Hall \& Lawrence, 1989 for a brief history of the field from the vantage point 30 years ago). What began decades ago as a coordinated attempt to stake out careers research as a domain of study continues today as an increasingly rich exploration of how people's careers develop over time and in relationship with the world around them. Evidence of this broadening of the field can be found in the sheer number and variety of research published in our top journals and presented at conferences. Part of this variety means that, just as it is difficult to paint "careers today" with one broad brush, it is nearly impossible to talk about one dominant approach to careers research. As the questions we ask about careers get more interesting, complicated, and layered, so too do the methodological approaches we use to explore career phenomena. Careers theories draw from fields as distinct as psychology, sociology, economics, and anthropology, each of which has its own rich methodological tradition (Arthur, Hall \& Lawrence, 1989; Dokko, Tosti-Kharas \& Barbulescu, 2020). Novel sources of data have been enabled by the same forces of technology and globalization that shift careers themselves. Researchers are availing themselves of the breadth and depth of data archived in corporate databases and on the Internet. They are collaborating on "mega-projects" that unite vast teams of scholars to compare results across contexts. Rather than utilizing primarily quantitative or qualitative methods, studies combine these approaches to maximum effect. The HR Department in many companies now includes Ph.Ds whose analysis of "big data" comprised of employees' career moves yields valuable insights (e.g., Duhigg, 2016). An important point of distinction between research on careers versus other topics within the management sciences is that every researcher has a career of their own that provides an opportunity for introspection and inspiration. Auto-ethnographic and narrative analyses can help us better understand what we can draw from our own careers (Belkhir et al., 2019). We see careers research becoming more divergent - not to the point of fragmentation, but rather to the point where these diverse approaches can complement and build upon each other.

Third, as careers researchers ourselves, we saw both symbolic and practical importance to having a dedicated collection of chapters exploring the best, most cutting-edge methodologies for studying careers. Despite the recognition that careers research is a defined area of study with all the trappings of one, including specialized journals and conferences - e.g., a particularly vibrant division within the Academy of Management, standing tracks at EGOS - there has not yet been a targeted volume to explore the breadth and variety of research methods within this area. We saw handbooks like this one for fields like human resource management and leadership, and wholeheartedly believed that there was both a desire and need for such a volume 
for careers. Frankly, this is the handbook we wish existed when we were embarking on our own career paths, as doctoral students, forging dissertations in this area.

We hope that you, as a reader of this Handbook, find the chapters collected here to be useful in your own research on careers. For scholars who are new to the field of careers, this collection of chapters should serve as a roadmap to the breadth of research methods in careers. Our authors present their methods in detail and offer numerous actionable best practices, realistic previews, and even cautionary tales based on their vast collective experience publishing in this area. For experienced researchers, we showcase the diverse and interdisciplinary approaches to designing projects and studying careers across the spectrum of quantitative and qualitative methodologies. We have chosen scholars to contribute to this volume who are not simply experts in the given methodology, but who have a track record of publishing cutting-edge research specifically in the area of careers. Therefore, these chapters are not written as generic explorations of a given method, but are intentionally situated within careers research. Together, the 58 authors who contributed to this Handbook represent institutions and organizations across 13 countries from a range of disciplinary training and an even wider range of national origins. The diversity inherent in our authorship reflects the diversity in careers research itself and provides further evidence of the rich heritage and future of the careers field.

\section{OVERVIEW OF CAREERS RESEARCH}

This Handbook starts with an extensive review of trends in career methods by Jos Akkermans, Colin I.S.G. Lee, Sanne Nijs, Aimilia Mylona, and Janneke K. Oostrom. Their chapter maps the methodologies most commonly used in research published in careers journals in the last five years, including the strengths and weaknesses of these methods, and identifies opportunities for future research. This chapter sets the stage for each series of chapters that follow to explore different approaches in-depth. The book is then organized into three parts on measurement and design, quantitative methods, and qualitative and mixed methods.

\section{Part I: Measurement and Design}

We begin the section on Measurement and Design with a thorough overview of constructs and key theories in the careers domain by Yehuda Baruch. In this chapter, theories such as boundaryless and protean careers are identified as well as related constructs such as global careers, mentoring, and work-life balance. The resulting list serves as an encyclopedia of terms and definitions and related challenges to their study. The chapter concludes with a discussion of how to study careers, matching empirical approaches to the research question and domain of interest, and addressing the "artificial divide" between quantitative and qualitative methodologies.

As this volume demonstrates, the breadth of career studies may necessitate teams of researchers to study trends, develop theory, validate constructs, and explore 
cross-cultural career issues. We have two chapters each introducing large-scale, multi-country, multi-year projects from a design perspective: the 5C Group and GETM3.

The 5C Group (Cross-Cultural Collaboration on Contemporary Careers) is composed of over 60 researchers organized into 30 country teams, and it continues to grow. Chapter authors Jon P. Briscoe, Michael Dickmann, Douglas T. (Tim) Hall, Emma Parry, and Wolfgang Mayrhofer explain that their objective is to "identify, develop and empower researchers in diverse parts of the world, to bring attention to diverse populations and their 'careerscapes,' and to contribute to efforts being more inclusive in social science research." The chapter briefly outlines the group's history and development of design principles for member selection, group norms, cultural, and methodological traditions. Attention to project design and intentional collaboration has resulted in over 20 articles and book chapters and over 30 presentations on their research around the world.

GETM3 (Global Entrepreneurial Talent Management 3) is an international, interdisciplinary funded research project bringing together 16 partners from five countries: the United Kingdom, Ireland, Poland, Slovenia, and the Republic of Korea (South Korea). In this chapter, 23 co-authors outline the project objectives, design, methodology, and participant experiences to illustrate the complexity and coordination required of a large, multi-year collaboration. A key objective is to "help people develop their knowledge, skills, and careers, while building links between organizations working in different sectors of the economy, including universities, research institutes, and SMEs" (European Commission, 2019). More importantly though, the chapter demonstrates how the GETM3 project serves as a bridge across national, sectoral, disciplinary, methodological, and career life stages as a vehicle for the career development of participants AND researchers themselves.

In studying career decision making, Gregory Hennessy and Jeffrey Yip explore the phenomenon of contingent employment in today's growing "gig economy." In this chapter, we see how design choices such as context are essential in enabling the researchers to explore constructs of interest in the careers domain. The chapter overviews the literature on career decision making and takes a deep dive into career decision making heuristics discussing types, rules, and options as well as the career decision making environment. It concludes with suggestions on how to study career decisions by applying real options theory in dynamic career environments.

Mentoring serves as an important source of professional learning and development in the careers domain. In their chapter on designing and studying mentoring programs, Rajashi Ghosh and Ague Manongsong demonstrate the very construct they study in their own co-author relationship of mentor and mentee respectively. This chapter provides a review of studies on formal mentoring programs in corporations, universities, professional associations, and with entrepreneurs; critiques the design of programs and methodological rigor of this area of research from an evidence-based perspective; and suggests how to improve both the design and study of programs as interventions in the workplace. 


\section{Part II: Quantitative Methods}

To begin the section on quantitative research methods in careers, Vladimer B. Kobayashi, Stefan T. Mol, Jarno Vrolijk, and Gábor Kismihók's chapter on text mining helps scholars avail themselves of the veritable bounty of textual data available today. The digitization of company personnel records coupled with data found across the Internet allows unique views into theoretical issues of interest to careers researchers. This chapter provides an approachable overview of the process of text mining and analysis, starting with acquiring the textual data, preparing the data for analysis, and then conducting the analysis. The authors provide an in-depth example of text analysis using the example of 50,000 job vacancy postings which are analyzed to shed light on salary.

Next, the chapter on conducting longitudinal research by Shoshana R. Dobrow and Hannah Weisman acknowledges that since careers by definition unfold over time, the methods we use to examine them should also build in this temporal component. Building on the authors' collective research spanning multiple years and data collections, the authors share practical advice for designing, conducting, analyzing, and ultimately publishing longitudinal research. In the process, they acknowledge the complexity inherent in managing such a project as well as the possibility of having to educate audiences less familiar with longitudinal methods as to the soundness of one's approach.

Individuals enact their careers embedded in personal and professional networks of relationships. In this chapter, Jessica R. Methot and Scott E. Seibert provide an introduction to social network analysis and develop a multi-level framework for organizing career-related network constructs. They review the study design, data collection needs, and network theory essential to exploring careers based on a social network analysis perspective. Their framework, which combines relational features (network composition, configuration, and content) and relational levels of analysis (individual, dyadic, and network), helps researchers situate their interests in this methodological toolbox. Social network analysis is a rich approach for examining a variety of topics in careers and provides many opportunities for understanding the changing nature of work.

Our understanding of contemporary careers can be improved by adopting a multi-level perspective. In this chapter, Bert Schreurs, Joeri Hofmans, and Bart Wille explain how individuals and organizations are nested within geographic boundaries, and time is nested within individuals. These complexities can be explored through multi-level modeling, which enables researchers to disentangle the effects of each level of analysis. The authors walk readers through this analysis in a step-by-step fashion, providing a clear rationale and a roadmap for fellow researchers. Finally, they discuss two opportunities for further research: individuals nested in occupations and individuals nested in romantic/partnership dyads. 


\section{Part III: Qualitative and Mixed Methods}

This section begins with a chapter by Kerry Roberts Gibson and Danna Greenberg presenting an overview of the importance and relevance of grounded theory research to careers scholars. In doing so, the authors discuss a novel, understudied aspect of performing grounded theory research, whether interview, archival, or participant-observation: the relationships the researcher has with a variety of elements of the research itself. In considering the relationship of the researcher to the underlying phenomenon of interest, to their research subjects, and to the eventual audience of the work, the authors provide concrete recommendations about how to best navigate these relationships, specifically the tensions and biases that are likely to accompany them. This chapter reveals an aspect of conducting primary research that is rarely talked about, yet extremely important to manage in practice.

Qualitative, in-depth interviews offer advantages in explaining career phenomena from an insider perspective. In this chapter, Suzanne C. de Janasz and A. Julie Katz reveal how in-depth interviews produce rich data reflecting the complexity of individuals' career experiences. Researchers gain a holistic view of beliefs, attitudes, decision making, and sense-making processes when participants have the opportunity to reflect on their behavior as well as their underlying motivations. The authors explore various approaches, from unstructured to semi-structured and structured interview protocols, and discuss options and decisions around the process before, during, and after the interview itself. In doing so, they build the case for in-depth interviews as an essential methodology for building theory and understanding the unique and evolving patterns of career.

In her chapter on narrative analysis, Holly Slay Ferraro provides a comprehensive look at how careers researchers can utilize this approach to better understand how people think about their careers over time. Importantly, she describes the ability of narratives to connect individual career identities with the institutions in which they are embedded, even as these connections change and shift. Drawing upon her own research on marginalized and stigmatized communities, as well as the work of others, the author explains how narratives allow people to tell their stories, allowing us to gain insight into populations we often overlook within careers research.

Applying a mixed method approach, Allison Creed and Susan Nacey examine metaphorical language usage in career-life preparedness, an important foundation for career development. The authors explain that "metaphor identification can open a window to deeper understanding of how individuals and organizations make meaning about education and career development over the lifespan." This chapter introduces a reliable and replicable procedure for metaphor identification, which they use to investigate career guidance discourse but could be applied across other contexts or career stages. Metaphor analysis is an innovative approach to examining career narratives with the potential to reveal new or unexplored concepts in the careers domain.

Careers are complex and interdisciplinary phenomena; thus Jelena Zikic and Viktoriya Voloshyna argue that mixed methods may be the most effective research 
approach. In this chapter, the authors discuss the myriad benefits of integrating different data collection techniques in one study to produce insights that go beyond a single approach. They review key journals in the careers field uncovering that the vast majority of papers are from a deductive, quantitative perspective. However, careers are dynamic and difficult to separate from the rich context in which they unfold, which makes qualitative data essential for understanding the multiple influences on careers. To provide further resources, they review exemplary studies employing mixed methods. Notably, the large scale projects (5C and GETM3) introduced in the section on measurement and design support this perspective as well. Thus, the consideration of how multiple methods provide a comprehensive lens on careers is a fitting conclusion to the Handbook.

\section{REFERENCES}

Academy of Management (2020). Careers. http://www.prcoeedings.aom.org/Content.aspx?id $=237 \#$ car.

Akkermans, J., Richardson, J., \& Kraimer, M. (2020). The Covid-19 crisis as a career shock: Implications for careers and vocational behavior. Journal of Vocational Behavior, 119, 103434.

Arthur, M. B., \& Rousseau, D. M. (1996). The Boundaryless Career: A new employment principle for a new organizational era. Oxford, UK: Oxford University Press.

Arthur, M. B., Hall, D. T., \& Lawrence, B. S. (1989). Generating new directions in career theory: The case for a transdisciplinary approach, pp. 7-25. In M. B. Arthur, D. T. Hall, \& B. M. Lawrence (Eds). Handbook of Career Theory. Cambridge, UK: Cambridge University Press.

Belkhir, M., Brouard, M., Brunk, K. H., Dalmoro, M., Ferreira, M. C., Figueiredo, B., Scaraboto, D., Sibai, O., \& Smith, A. N. (2019). Isolation in globalizing academic fields: A collaborative autoethnography of early career researchers. Academy of Management Learning \& Education, 18(2), 261-285.

Biemann, T., Fasang, A. E., \& Grunow, D. (2011). Do economic globalization and industry growth destabilize careers? An analysis of career complexity and career patterns over time. Organization Studies, 32(12), 1639-1663.

Boveda, I., \& Metz, A. J. (2016). Predicting end-of-career transitions for baby boomers nearing retirement age. The Career Development Quarterly, 64(2), 153-168.

Briscoe, J. P., Henagan, S. C., Burton, J. P., \& Murphy, W. M. (2012). Coping with an insecure employment environment: The differing roles of protean and boundaryless career orientations. Journal of Vocational Behavior, 80(2), 308-316.

Cappelli, P., \& Keller, J. R. (2013). Classifying work in the new economy. Academy of Management Review, 38(4), 575-596.

Dokko, G., Tosti-Kharas, J., \& Barbulescu, R. (2020). Bridging micro and macro: An interdisciplinary review of theories used in career studies, pp. 25-41. In H. Gunz, M. Lazarova, \& W. Mayrhofer (Eds). The Routledge Companion to Career Studies. London, UK: Routledge.

Duhigg, C. (2016). What Google learned from its quest to build the perfect team. The New York Times Magazine, February 25, 2016.

European Commission (2019). Research and innovation - Participant portal 2020 online manual. http://ec.europa.eu/research/participants/docs/h2020-funding-guide/cross-cutting -issues/gender_en.htm. 
Michaelson, C., \& Tosti-Kharas, J. (2020). A world changed: What post-9/11 stories tell us about the position of America, purpose of business, and meaning of work. Academy of Management Review, advanced online publication.

Ng, E. S. W., Schweitzer, L., \& Lyons, S. (2010). New generation, great expectations: A field study of the Millennial Generation. Journal of Business and Psychology, 25(2), 281-292.

Petriglieri, G., Ashford, S. J., \& Wrzesniewski, A. (2019). Agony and ecstasy in the gig economy: Cultivating holding environments for precarious and personalized work identities. Administrative Science Quarterly, 64(1), 124-170.

Schwab, K. (2016). The Fourth Industrial Revolution. New York: Crown.

Spreitzer, G. M., Cameron, L., \& Garrett, L. (2017). Alternative work arrangements: Two images of the new world of work. Annual Review of Organizational Psychology and Organizational Behavior, 4, 473-499.

Spurk, D., \& Straub, C. (2020). Flexible employment relationships and careers in times of the COVID-19 pandemic. Journal of Vocational Behavior, 119, 103435.

Tams, S., \& Arthur, M. B. (2007). Studying careers across cultures. Career Development International, 12(1), 86-98. 